\title{
MEDYA SEKTÖRÜNDE BİR UZMANLAŞMA OLGUSU OLARAK TEMATIK KANALLAR VE iZLEYici ÇEŞiTLiLIĞiNIN TEMATiK KANAL OLUŞUMUNDAKi ROLÜ
}

\author{
EMINE SAYILGAN*
}

\begin{abstract}
ÖZET
Genel kitleleri hedef alan televizyon kanallarının reyting kaygısıyla yapmış oldukları yayınlar ve izleyiciyi bunaltan reklam yayınları, izleyicileri daha seçici olmaya itmiştir. Farklı demografik özelliklerdeki izleyicilerin farklı beklenti, talep ve tercihleri vardır. Yıllar içinde televizyon yayıncılığında teknolojinin gelişmesiyle kanal sayılarındaki artış, yayıncıların izleyicilerin isteklerini yerine getirmesinde en büyük etken olmuştur. Yayıncılar hedef kitleleri farklı bölümlere ayırarak, farklı izleyici kitlelerine farklı temalarda (konularda) yayınlar yapmaya başlamışlardır. Böylelikle daha geniş bir yelpazede bulunan genel izleyici kitlesi, tematik yayıncılık anlayışı doğrultusunda daha küçük ancak nitelikleri ve talepleri benzer gruplara bölünmüştür. Tematik kanallar kendi hedef kitlesini daha tatmin edebileceği biçimde oluştururken, izleyiciler de tercih ve seçim şanslarının arttırılması olanağına kavuşmuşlardır. Bu çalışmada dijitalleşme sonucunda oluşan kanal sayılarındaki artış ile izleyicilerin farklı istekleri doğrultusunda gelişen tematik (konulu) kanallara yönelmeleri incelenmiştir. Ayrıca tematik kanalların sayıları, türleri ve finansman kaynakları çeşitli ülkelerden verilen örneklerle analiz edilmiştir.
\end{abstract}

Anahtar Kelimeler: Tematik Kanal, Dijitalleşme, İzleyici Çeşitliliği

\section{THEMATIC CHANNELS AS A SPECIALIZATION PHENOMENON IN MEDIA SECTOR} AND THE ROLE OF VIEWERS VARIETY ON THE THEMATIC CHANNEL IN FORMATION

\section{ABSTRACT}

Viewers preferences, expectations and desires have changed over the years. Television viewers began to become more selective. Viewers want to watch programs that are more qualified and preferred. The development of technology over the years has increased the number of television channels. This situation has created an advantage and television broadcasters have begun to reach out to different audiences in different thematic channels. According to the different demands of television viewers is divided into different segments. And now all channels have increased along with options. In this study the increase of thematic channels whic has occurance of the result of digitalization and the structure of thematic channels which has developed towards the viewewr's different demands have examined. And also thematic channels' numbers, kinds and financial resources have analyzed which have given examples from different countries.

Key Words: Thematic Channel, Digitalization, Variety of Viewer

*Doç.Dr., Marmara Üniversitesi İletişim Fakültesi, Basın Ekonomisi ve İşletmeciliği A.B.D., esayilgan@marmara.edu.tr 


\section{Giriş}

TV izlemek hemen hemen tüm ülkelerde birçok insan için önemli bir faaliyet özelliği taşımaktadır. Yapılan birçok çalışma ve araştırmalara göre TV izlemek ön önemli boş zaman değerlendirme şeklidir (Corneo, 2005: 99). 1995 yılında bir Amerikalı haftada ortalama 16 saat, bir günde ise ortalama 2 1/4 saat TV izlemektedir. 90'ların sonuna gelindiğinde birçok Avrupa ülkesinde (Danimarka, Finlandiya, Belçika, İsveç, Büyük Britanya, Fransa, Macaristan, Estonya, Slovenya) günde ortalama 2-2 3/4 saat, haftada ise ortalama 14-19 saat TV izlenmektedir (Aliga ve Winqvist, 2003). 2002 ve 2003 yıllarında Avrupa genelinde yapılan bir anket çalışması (European Social Survey), anketi cevaplayanların \%20'sinin günde 3 saatten fazla bir zamanı TV izleyerek geçirdiklerini göstermektedir (Frey, Benesch, Stutzer, 2007: 286). Yıllar içerisinde TV izleme oranlarında artış devam etmiş ve 2005 yılındaki IP Germany verilerinde, insanların Avrupa'da günde ortalama 226 dakika, Amerika Birleşik Devletleri’nde ise günde ortalama 297 dakika TV izlediği ortaya konmuştur (IP Germany, 2005).

Yüzüncü Yıl Üniversitesi Radyo Televizyon Bölümü'nce yapılan 26 ili kapsayan 2008 yılı televizyon izleyicisi araştırmasında, Türkiye'de de televizyon izleme süresi batılı ülkelerden geri kalmamakta, televizyon izleyicisinin doğrudan bir amaç gütmeksizin zaman geçirmek için televizyon izlediği görülmektedir. Ayrıca Türk toplumunun günlük ortalama 3 saatten fazla TV seyrettiği de bu araştırmada saptanmıştır (www.medyaa.com, 26.02.2010). 2013'ün ilk aylarında Radyo Televizyon Üst Kurulu'nun (RTÜK) “Televizyon İzleme Eğilimleri-3 Araştırması"na göre hafta içi kadınların ortalama 3.8 saat, erkeklerin ise 3.6 saat televizyon izledikleri tespit edilmiştir. Hafta sonunda bu oranın daha da yükseldiği ve ortalamada 4 saati geçtiği görülmektedir (http://www.turkiyegazetesi.com.tr/, 02.05.2013). Aynı araştırmada bilgisayar üzerinden televizyon izleme oranında da artış olduğu belirtilmektedir.

TV izleme sürelerini içeren yukarıdaki veriler standart neoklasik ekonomi teorisiyle açıklanabilir. Bireyler neyin kendilerine en iyi faydayı yaratacağını bildiklerini varsayarlar ve kendilerine en uygun TV tüketim süresini seçmekte özgürdürler (Frey, Benesch, Stutzer, 2007: 284). Bireylerin zaman içerisinde daha 
fazla TV seyretmesini destekleyen faktörler arasında içerik, çeşitlenme, farklılık ve daha fazla kanala erişim kolaylıkları bulunmaktadır. Özellikle 1990'lardaki liberalleşme rüzgarıyla Avrupa'da yerli ticari kanal yayıncılarının sayısında bir artış olmuş ve bu artış televizyon piyasasındaki rekabetin ulusal ve yerel kanalların ve programların sayısındaki artış olarak süregelmesine sebep olmuştur (Council of Europa, 1998; Davis, 1999).

Kanal sayısındaki artış izleyici ve reklamcı davranışlarında da değişikliklere sebep olmuştur. İzleyiciler TV izleme tercihlerini güncelleyip, çeşitlendirirken, reklamcılar da hedef kitleye ulaşmak ve reklam harcamalarını daha etkin kullanabilmek adına farklı kanallara yönelmişlerdir. Bu gelişmeler çoklu kanal televizyon tercihi imkanını izleyiciye sunarken, televizyon piyasasının rekabet şartlarını değiştirmiş ve televizyon yöneticilerini sayıca fazla olan kanallarını finanse etmek yönünde farklı stratejiler geliştirmeye yöneltmiştir.

Tematik kanalların sayı ve çeşitlerinin artmış olmasına rağmen, yeterince büyüyememeleri temel sorunu oluşturmaktadır. Bu çalışmada televizyon kanal sayılarındaki artışa en büyük etken olan dijitalleşme ile buna bağlı olarak kanal sayılarının artarak çeşitlenmesi ve izleyici talepleri doğrultusunda gelişen tematik (konulu) kanalların oluşumları sebep sonuç ilişkisi yönünden incelenecektir. Ayrıca tematik kanalların sayıları, türleri ve finansman kaynakları çeşitli ülkelerden verilen örneklerle analiz edilecektir.

\section{Dijitalleşme ve Kanal Sayılarındaki Artış}

Dijital yayıncılık alanındaki çalışmalara 1990 yılında başlanmıştır. 90'lı yılların sonunda dünya üzerindeki büyük bir kesimde kablo ve karasal yayınlar analog bir şekilde yayınlarına devam ederken, uydu yayınlarının büyük oranda dijitalleștiği görülmektedir. Geleceğin, dijital görüntü ve ses iletiminde olduğu kesin bir şekilde ispatlandıktan sonra kablo ve karasal yayıncılık hizmetlerinde de dijital yayıncılığa geçilmiştir. Dijital televizyon yayıncılığı kullanıcılara daha kaliteli görüntü ve ses getirmiştir. Uydu üzerinde ve kabloda yayınların taşıdığı kanal kapasitesini arttırmıştır. Uydu aktarıcısından (transponder) sadece 1 analog televizyon kanalı yayını yapılabilirken, dijital teknoloji aynı aktarıcıdan daha kaliteli 
olarak, 4 ayrı televizyon kanalının yayın yapmasını sağlamış ve bu da 4 kat daha fazla izleyici ve 4 kat düşük maliyeti getirmiştir (Eldeniz, 2003: 13). Dijital televizyon ve analog televizyon yayınları birçok çalışmada incelenmiş (Parker, 1999; Chalaby ve Segell, 1999; Richeri, 2001; Prario, 2003) ve dört ana fark üzerinde birleşilmiştir. Bunlar:

- Dijital yayın, aynı transponder (uydu aktarıcısı) üzerinde çoklu televizyon kanalı yayını yapılmasını sağlamıştır.

- Analog yayınlarda atmosferik şartlardan ve iletim ağı hatalarından dolayı oluşan parazitlerin, gürültülerin giderilmesi mümkün olmamasına karşın, dijital yayın teknolojisinde, her türlü parazit ve gürültü giderilerek çok daha temiz ve hatasız iletişimi sağlamak mümkündür.

- Dijital yayıncılık, etkileşimliliŭi ve karşılıklı veri iletimini getirmektedir.

- Dijital yayınc1lıkta dijital kodlu görüntü ve sesler, mevcut tüm iletim ağlarına (kablo televizyon, uydu ve karasal yayını) uyumlu olması yanında, bir telefon bağlantısıyla televizyonu internete bağlayarak interaktif hizmetlere erişimi sağlamaktadır.

Dijital yayıncılığın sağladığı çeşitli yararlardan dolayı, kablo, uydu ve karasal yayınlar iletim şekli olarak dijital yayıncılığa yönelmişler ve böylece kanal sayısı her yıl biraz daha artmıştır. European Audiovisual Observatory tarafından açıklanan verilere göre 2008 yllında 27 Avrupa Birliği ülkesi ve iki aday ülke (Türkiye ve Hırvatistan) genelinde 6500 kanal olduğu belirtilmiştir ( European Commission, 2008). Bunlardan 5068 tanesi aktif durumda bulunmaktadır ve 4663 adedi $27+2$ aday Avrupa Birliği ülkelerinde kurulmuş, 405 adedinin ise kuruluş yerleri birliğe bağlı ülkeler dışındaki farklı ülkelerdir.

4663 Avrupa kanalının yayın şekli dağılımı (European Commission, 2008):

- 381 ulusal karasal kanal (Analog veya dijital ulusal lisansa sahip)

- 2473 ulusal boyutta kablo, uydu veya IPTV (Bunların 656 tanesi bir ülkede kurulup, bir veya daha fazla sayıda ülkeyi hedefleyen kanallar) 
- 1809 bölgesel veya yerel kanal.

Kanallardaki artış 2009 yılında da ekonomik krize rağmen devam etmişstir. Dijital televizyon yayıncılığı, “öde-seyret” şeklinde yayın yapan kanalları (Pay TV), internet üzerinden televizyonculuğu (IPTV) ve cep telefonundan izlenen kanallar (mobile TV) gibi mecraları geliştirmiştir (European Commission, 2010).

2009 yılında 2008 yılına göre kablo operatörlerinde küçük bir gerileme görülürken diğerlerinde artış olduğu gözlenmektedir. Ayrıca 2009'un sonunda Avrupa'da (Birlik ülkeleri +2 aday ülke, Türkiye ve Hırvatistan) televizyon kanalı sayısı 7200'den fazla bir rakama ulaşmıştır (European Commission, 2010).

Kanal sayısının artması ve ticarileşmeyle birlikte, kanallar farklı şekilde yayın politikaları geliştirmişlerdir. Bu farklılaşmayı European Audiovisual Obsevatory altı ana kategoriye bölmüştür (Lange, 2005):

- Kamu radyo-televizyon kuruluşları (SPTV)

- Reklamla finanse edilen özel TV kuruluşları (ADTV)

- Öde-seyret şeklindeki TV kuruluşları (PAYTV)

- Program paketi satan TV kuruluşları (PACKTV)

- Tematik televizyon kuruluşları (THTV)

- Alışveriş yapılan TV kuruluşları (HSTV)

Tüm TV kanalları arasında tematik televizyonlar istikrarlı bir büyümeye sahip olmuşlar ve dijitalleşmenin bir lütfu olarak ortaya çıkan tematik kanallar günümüzde de artışını devam ettirmektedirler.

\section{Tematik Kanallar ve TV İzleyicisinin Farklı Gruplara Bölünmesi}

Dijitalleşme ve kanalların çoğalmasıyla birlikte geleneksel televizyon kuruluşlarından (kamu yayıncıları, ticari yayıncılar ve pay-TV) farklı olarak yeni bir tür televizyon yayıncılığı ortaya çıkmıştır. Bu yeni TV'nin temel amacı sadece program sunmak değil aynı zamanda hizmet de sunmaktır. Bu tür kuruluşlar kablo, uydu ve havadan yayın yapabilen ve çok sayıda kanala sahip olan kuruluşlardır. Her kanal tematik (özel bir konuya odaklanmış) özellikler göstermekte ve farklı 
bölümlere ayrılmış (yaş, cinsiyet, eğitim düzeyi gibi daha homojen gruplar) hedef kitleye program sunmaktadır (Dosi ve Prario, t.y.: 651).

Günümüzün rekabetçi piyasalarında başarıya ulaşabilmek için müşteri odaklı olmak, mevcut müşteri ve tüketicileri sadık hale getirebilmek ve aynı zamanda yenilerini kazanmak en önemli pazarlama faaliyetlerinden birisi olarak görülmektedir. Müşterileri memnun etmek için de öncelikle onları anlamak ve tanımak gerekmektedir. Müşteri ve hedef kitlenin ihtiyaçları, istekleri, satın alma güçleri, hayat tarzları ve algıları değiştiği için tek bir müşteri veya hedef kitle yapısından bahsetmek imkansızdır. Bunun için öncelikle yapılması gereken müşteri ve hedef kitleyi farklı bölümlere ayırmaktır (Bal, http://www.soruman.com/ 20.02.2010). Televizyon yayıncılı̆̆ında da modern pazarlama stratejileri arasında en önemli adımlardan birisi hedef kitleyi bölümlere ayırmak ve hedefe odaklanmak olarak görülmektedir.

Tematik kanallar genel izleyici kitlesi yerine, özel izleyici gruplarına yönelen ve onların beğenilerine uygun temalarda yayın yapan televizyon kanalları olarak tanımlanabilir (Çelikcan, 2001). Tematik kanallar genel içinden seçilmiş, ortak özellikleri bulunan, sayıca daha az bir kitleye hitap ederler ve program içeriklerini de bu ortak özellikler belirler. Uzmanlık kanalları da denilen tematik kanallar televizyon sektöründe içeriği ön planda tutarak, reyting kaygısından uzak yayınlar yapma çabasındadırlar.

Tematik kanalların oluşumunda en önemli unsurlardan birisi teknoloji, bir diğeri ise izleyicinin isteklerindeki farklılaşma ve çeşitlenmedir. İzleyici daha kaliteli ve ilgi alanına giren programları tercih etmeye başlamıştır. Kuşkusuz bunun en büyük sebebi, ulusal ya da popüler kanal olarak adlandırılan büyük kanalların programlarının, izleyiciyi reklam bombardımanına tutması, haber programlarının bile magazinleşmesi ve reyting savaşlarının izleyiciyi iyice bunaltmasıdır (www.cihandergi.com, 12.12.2009).

Bachschmidt'e göre tematik kanal sektörünün yıllar içinde yavaş yavaş ancak istikrarlı bir şekilde gelişmesi, birtakım davranış kalıplarına bağlıdır ( 2003: 145): 
- Az sayıda "güçlü ve marka haline gelmiş", popüler tematik kanallar birbirleriyle zorlu bir rekabet içindedirler. Bu tür kanalların hedefi kitle halindeki izleyicilerdir. En basit program paketlerinin parçası veya "seçenek" olarak pazarlanırlar.

- Diğer taraftan yıllık bütçeleri 6 veya 8 milyon EURO arasında değişen "küçük tematik kanallar" ve onların program içerikleri daha niş (daha önce hizmet sunulmamış) izleyicileri hedeflemektedir. Böylece bir ihtiyacı yerine getirmiş olurlar. Bu tür kanallar genelde "seçenek" olarak tercih edilebilirler ancak bir program paketinin parçası olamazlar.

- Üstteki iki tematik kanal türünden başka, yıllık bütçeleri 8 ile 15 milyon EURO arasında değişen "orta büyüklükteki tematik kanallar", açık olmayan bir konumlama sergilerler. Bu tür kanalların geleceği güçlü bir kurum desteği olmadıkça belirsiz olacaktır.

Tematik kanallar sayı olarak artış gösterdikleri gibi, tür olarak da birçok farklı kategoriye bölünebilirler. Tür olarak ortaya çıkan çeşitlilik artışı izleyicinin bölümlere ayrılması ile ilgilidir. Günümüzün yoğun rekabet şartlarında, firmalar tüketicinin artan istek ve ihtiyaçlarını daha çok dikkate almaya başlamışlardır. Firmalar genellikle homojen bir piyasa yapısının var olmadığını fark ederek, farklı istekleri, karakterleri, davranışları olan ve bu özelliklerine uygun ürün ve pazarlama bileşenleri isteyen, farklı müşteri gruplarının olduğunu görmüşlerdir (Kotler, Armstrong, 1996). Bu durum hedef kitleyi bölümlere ayırmanın temelini oluşturmaktadır. Bir pazarı bölümlere ayırmak hem tüketiciler hem de firmalara etkili pazarlama stratejileri tasarlamak ve uygulamak için imkan vermektedir. Pazar bölümlere ayrıldığı takdirde firma, pazarın tümüyle rekabet etmek yerine, hedef olarak belirlediği bir kısmına daha iyi hizmet vererek, rekabet konumlamasını "ürün” üzerine yoğunlaştırmaktadır (Kotler, Armstrong, 1996).

\section{Tematik Kanalların Gelişimi ve Genel Kanallardan Ayrılan Özellikleri}

Öncelikle yayın teknolojisindeki değişmeler ve hedef kitlenin farklı özelliklerine dayalı farklı beğeni ve ihtiyaçlarının giderilmesine yönelik tematik yayıncılığın ortaya çıkmasıyla, yayıncılıktaki temalar da çeşitlenmiştir. Kadın, erkek, 
yaşlı, genç, çocuk gibi farklı hedef kitlelere yönelik yayın yapan tematik kanalların yayınlarını grupladıkları genel temalar; haber, spor, film ve dizi, çocuk, müzik, belgesel, yaşam ve eğlence ile erotik kanallardır. Her bir temanın kendi içinde daha farklı alt temalara da ayrılmasıyla (moda, doğal yaşam, hobi, taraftar kanalları vb.) hedef kitlenin çok daha küçük bölümlerine yayın yapıldığg görülmektedir.

Tematik televizyon yayınları Amerika'da başlamış, daha sonra uluslararası boyutlarda yayın yapan televizyon kanallarına dönüşmüştür. 1980'li yıllarda ESPN spor, C-SPAN haber, Nickelodeon çocuk alanında tematik kanal olarak kurulmuştur. İlerleyen yıllarda MTV müzik alanında, CNN'de haber kanalı olarak ulusal yayın yapmak üzere kurulmuş ancak daha sonra uluslararası boyut kazanarak (MTV Europe, CNN-I) dünyanın en çok izlenen tematik kanallarını oluşturmuşlardır (Çelikcan, 2001). Günümüze gelinceye kadar daha yerel kalan tematik kanallar yanında, izleyicisi milyonları bulan özellikle spor, haber, çocuk, müzik, erotik ve sinema alanında uluslararası yayın yapan dev bütçeli tematik kanallar oluşmuştur.

Türkiye'de tematik kanalların ilk örnekleri kamu yayıncılığı alanında TRT tarafından gerçekleştirilmiştir. TRT2 kültür-sanat kanalı olarak yayın yapmaya başlamış, akabinde TRT3 ve TRT4 farklı alanlarda farklı hedef kitlelerle buluşmuştur. Özel televizyonculuğun önünün açılmasıyla ilk özel tematik kanal olarak müzik alanında yayın yapan Kral TV yayına başlamıştır. 1990'lı yılların sonu ile 2000'li yıllarda çok sayıda tematik kanal açılmıştır. Yayına başlayan tematik kanalların çoğu kablolu yayın teknolojisinin kısıtlılığından dolayı dijital yayın platformları üzerinden yayın gerçekleştirmişlerdir. Zamanla oldukça uzmanlaşan tematik kanallar kablolu yayınların dijitalleşmesiyle bu platformlarda da sayılarını arttırmışlardır. Aşağıdaki tabloda Digitürk dijital yayın platformu üzerinden yayın yapan tematik kanalların temalarına göre ayrımı ve kanal isimleri görülmektedir. 
Tablo: Ekim 2013 Digitürk Dijital platformunda yayınlanan tematik kanallar ve temaları

\begin{tabular}{|c|c|}
\hline TEMALAR & KANALLAR \\
\hline Haber & $\begin{array}{l}\text { Bloomberg HT, A Haber, Ülke TV, 24, NTV, CNNTürk, } \\
\text { SkyTürk, HaberTürk, TGRT Haber, S Haber, Olay TV, } \\
\text { Bloomberg, BBC World News, Euronews, AL Jazeera } \\
\text { English }\end{array}$ \\
\hline Spor & $\begin{array}{l}\text { Fox Sports, Eurosports, Eurosport 2, Bursaspor TV, } \\
\text { BJK TV, GS TV, FB TV, Lig TV, Lig TV2, Lig TV3, NTV Spor, } \\
\text { TJK Spor, Sports TV, Extreme Sports, ESPN America, ESPN } \\
\text { Classic, TRT Spor, Taraftar 204, Taraftar 205, Lig TV Ticari, } \\
\text { Lig TV2 Ticari, Lig TV3 Ticari }\end{array}$ \\
\hline Film\&Diziler & $\begin{array}{l}\text { Salon 1, Salon 2, Salon 3, Fox Life, Dizimax Comedy, } \\
\text { Dizimax Vice, Dizimax Drama, Sundance Channel, MGM } \\
\text { Movies, MMX Family, MMX Premier, Stars, Festival, } \\
\text { Speed, Türkmax }\end{array}$ \\
\hline Çocuk & $\begin{array}{l}\text { TRT Çocuk, Baby TV, Disney XD, Planet Çocuk, Baby } \\
\text { First, Disney Junior, Jojo, Disney Channel, Yumurcak TV, } \\
\text { Cartoon Network, Minikago, Nick Jr. Nickelodeon, }\end{array}$ \\
\hline Müzik & $\begin{array}{l}\text { Fog TV, Dream TV, PWRTR, MCM Top, Mezzo, VH1, } \\
\text { Trt Müzik, Kral Pop, Kral TV, MTV, MTV Hits, Alem FM, } \\
\text { Süper FM, Joy Türk, TRT Nağme, TRT Türkü, Radyo 34, } \\
\text { Metro FM, Joy FM, Radyo İmparator, Blues, (ilave } 30 \\
\text { değişik müzik kanalı) }\end{array}$ \\
\hline Belgesel & $\begin{array}{l}\text { İ, NAT GEO ADV, Nat Geo, Nat Geo Wild, CBS } \\
\text { Reality, History, TRT Belgesel, Discovery Channel, } \\
\text { Discovery Science, Animal Planet }\end{array}$ \\
\hline Eğlence & $\begin{array}{l}\text { Fashion TV, Home TV, E! Entertainment, FX, Style } \\
\text { Network, World Travel, Dizimax Entertainment, Showmax, } \\
\text { MCJ }\end{array}$ \\
\hline Erotik & Blue Hustler, Intımacy, Playboy, Penthouse, \\
\hline
\end{tabular}

Kaynak: "http://www.digiturk.com.tr" sitesinden derlenmişsir.

Tematik kanalların belirli hedef kitlelere yönelik yayınları yanında, genel kapsamlı yayın yapan televizyon kanallarından ayrılan bir takım farklı yönleri de vardır. Bunlar; izleyiciyi konumlandırdıkları biçim yönünden, reklamın programlaşması yönünden ve reklam politikaları yönünden olmak üzere üç şekilde siralanabilir. 


\subsection{Tematik Kanallarda İzleyici Konumlandırması}

Dijitalleşme ile teknolojik zemine kavuşan tematik televizyonculuk, özel televizyonculuğun da artışıyla sayısal olarak bir patlama yaşamıştır. Özel televizyonculuğun gelişmesi tematik kanalları arttırırken, izleyiciye bakış açısının da değişmesine sebep olmuştur. Kamusal yayıncılık izleyiciyi "yurttaş” olarak görürken, özel televizyonculuk izleyiciyi tüketici yani "müşteri” olarak görmektedir (Çelikcan, 2001). Kamu yayıncılığı ilkesine göre televizyonculuk yarı kamusal bir işlevi yerine getirirken, izleyicileri de birer yurttaş olarak eğlendirip, bilgilendirip, geliştirmeye çalışmaktadır.

Özel televizyonlar ise daha çok ticari birer kurum olarak faaliyet gösterdikleri için hedef kitlelerini müşteri olarak konumlandırmaktadırlar. Yurttaş kavramının içerisine benzer ard alanlar, ortak ve birbirine benzeyen özellikler dahil edilebilirken, müşteri kavramı daha birbirinden ayrılan beğeni, beklenti ve isteklerin olduğu özellikleri çağrıştırmaktadır. Böylece birbirinden ayrılan beğeni, beklenti ve istek sahibi farklı demografik özelliklerdeki izleyiciyi aynı programlarda buluşturabilmek oldukça zor görülmektedir (Çelikcan, 2001). Bu nedenle birbirine benzemeyen özellikler taşıyan izleyici kitlesini benzer programları izlemeye yöneltmektense, farklı özellikler taşıyan ve beklentileri aynı olan, daha küçük ve daha homojen izleyicileri değişik içerikli yayınlara yönelterek, onların reklam verene pazarlanması daha kolay görünmektedir. Müşteri olarak konumlandırılan izleyicilerin beğenilerinin ve demografik özelliklerinin reklam verene pazarlanmasıyla bu kanallar para kazanmaktadırlar. Programın içeriği ve yapısıyla birebir örtüşen izleyici kitlesi sayıca az bile olsa, reklam veren için en uygun kitle olabilmektedir.

Yayıncı için izleyicinin müşteri olarak görülmesindeki bir diğer sebep ise, genellikle tematik içerikli kanalların çoğunun bir ücret karşılığında abone olunan platformlarda yayınlanıyor olması ve izleyicinin müşteri gibi yayını izleyebilmek için para ödemek zorunda kalmasıdır.

\subsection{Tematik Kanallarda Reklam Politikaları}

Geniş izleyici kitlelerine yayın yapan televizyon kanallarının izleyici kitlesi daha çeşitli demografik özelliklere sahip ve daha heterojen bir yapıdadır. Bu tür 
kanalların reklam verenden reklam alabilmedeki en büyük kozu programlarının izlenme oranı yani reyting ölçüsüdür. Reklam verenler reytinge göre reklam verdiğinden, geniş izleyici kitlesi içinden ulaşabileceği en üst orandaki izleyici sayısı ile amaçlarını gerçekleştirmeyi hedeflerler. Seçilmiş hedef kitlelere yayın yapan tematik kanallarda ise izleyicinin miktarından çok niteliği ön plana çıkmaktadır. Reklam veren açısından reklamını yapmak istediği ürün veya hizmet ile hedef kitlenin yani izleyicinin uyumu oldukça önemlidir. Örneğin eğitim ve gelir düzeyi yüksek, yönetici pozisyonundaki bir meslek grubuna yönelik bir tematik kanalı tercih eden reklam veren için, ürünlerinin hedef kitleyle birebir uyumu, reytingi yüksek bir programdan daha avantajlı duruma gelebilir.

Türkiye'de ölçüm yapan iki reyting şirketinden SBT, TRT'nin çocuk ve spor kanallarının ölçümünü ilk 100 program arasında gösterirken, farklı tematik kanalların ölçümü bu sıralamada bulunmamaktadır. Diğer ölçüm şirketi TNS ise ilk 100 program sıralamasında tematik kanalların reyting ölçümlerinin hiç birisini yansıtmamaktadır. Reyting ölçüm sıralaması ve rekabetine her ne kadar dahil olmasalar da, uzmanlaşmış yayınları ve seçilmiş temaları dolayısıyla tematik kanallar, reklam verenler için cazip görünmektedir. Ancak klişe bir yaklaşım olan “yüksek reyting” tercihi reklam vereni hala daha geniş kitlelere seslenen popüler kanallara yöneltmektedir. Ayrıca tematik kanalların yayın platformları olan kablolu yayın ve dijital yayın platformlarının desteğinin tematik kanallara az olması da bu kanalların, daha sınırlı reklam almalarına sebep olmaktadır. Oysa reklam fiyatlarının diğer popüler ve geniş tabanlı kanallarla kıyaslandığında çok daha cazip olduğu bilinmektedir. $\mathrm{Bu}$ sebeple tematik kanallarda gelir elde etmek, yayınları sürdürebilmek adına "sponsorluk" önem kazanmıştır.

Reklam açısından cazip yönleri olmasına rağmen, "yerel” boyuttaki tematik kanallar için reklam alabilmek büyük bir sıkıntıdır. Dünyada birçok ülkeye yayın yapan ve çok izlenen tematik kanallar ise, reklam veren için daha farklı bir konumdadır. Eurosport, Nickelodeon, CNN I gibi tematik kanallar çok uluslu markalar için vaz geçilmez reklam mecralarıdır. Ancak bunların da sayısı oldukça sinirlidir. 


\subsection{Tematik Kanallarda Reklamın Programlaşması}

Tematik kanalların temel işlevleri seçilmiş bir hedef kitleye, seçilmiş bir temada yayın yapmaktır. Bu tür yayınları yaparken de ayakta kalabilmek adına reklama ihtiyaçları vardır. Genel yayıncılık yapısında program aralarına, programdan kesin sınırlarla ayrılmış reklam yayınlarının verildiği görülmektedir (Çelikcan, 2001). Tematik kanal yayınlarında da bu tür program-reklam ayrımı olmakla birlikte, bazen reklamların başlı başına program gibi verildikleri görülmektedir.

Özellikle, müzik kanallarında, alışveriş kanallarında ve moda kanallarında sıklıkla reklam ve program iç içe geçmiştir. Müzik yayını yapan kanallar çoğu zaman bir albüme veya sanatçıya program yaparak, hem bunu bir program olarak sunmakta hem de albümün tanıtımını yapmaktadırlar. Böylelikle program reklamla kesintiye uğramadan, hem reklam yapılmakta hem de program yapılmaktadır (Çelikcan, 2001).

Benzer durum, yirmi dört saat yayın yapan Fashion TV'de de görülmektedir. Hiç reklam arası vermeden değişik modacıların ve markaların ürünleri hem reklam, hem de program olarak sunulmaktadır. Yirmi dört saat programlaşmış reklam yayını yapan diğer tematik kanallar ise tele-alışveriş olarak adlandırılan alışveriş kanallarıdır. MCJ, Top Shop TV gibi kanallar bu tür kanalların önde gelen örnekleridir. MCJ Asya ülkelerinin önde gelen tele alışveriş kanalı iken, Türkiye pazarına da girmiş ve Türkiye'deki hedef kitleye de ulaşmayı başarmıştır. Reklam yönü ağır basan bu tür programlarda sponsorluk yaygın biçimde kullanılmaktadır.

\section{Sonuç}

İzleyiciler arasında, farklı grupların farklı beklentilerinin olması, izleyicileri daha seçici olmaya yöneltmiştir. İzleyiciler daha nitelikli programlara ve çeşitliliğe önem vermeye başlamışlardır. Geniş kitlelere hitap eden genel kanallar ya da popüler kanallar reyting kaygısı ve reklam bombardımanlarıyla izleyiciyi bunaltmış ve bir arayışa itmişlerdir. İzleyicinin daha seçici olan bu tür talepleri teknolojinin sunmuş olduğu imkanlarla birleşince doğal olarak tematik kanallar ortaya çıkmıştır.

İzleyici kitlesine demografik özelliklerine, yaşam biçimlerine ve tercih çeşitlerine göre farklı temalarda yayın yapan tematik kanallar, yıllar içinde hem nicelik olarak, hem de nitelik olarak daha da uzmanlaşmışlardır. Teknolojinin 
ilerlemesi ve internetin hayatımıza hızla girişiyle televizyon kanallarının internet üzerinden izlenmesi televizyonculuğun günümüzde geldiği son durumlardan birisidir. Tivibu, Tiviyo, DigitürkPlay gibi internet üzerinden yayın yapan televizyonların yayını durdurup geri alma özellikleri, kaydetmeden programı izleme olanağı, yorum ve mesaj yazma gibi interaktif özellikleri bulunmaktadır. Daha "kişisel televizyon" olarak nitelendirilebilecek bu tür televizyon yayın teknolojisinde "seç izle, durdur izle, geri al izle, tekrar izle" gibi özellikler bulunmaktadır. Web uygulamalar yanında, android işletim sitemine sahip mobil cep telefonu ve tablet uygulamaları da bulunan bu şekildeki televizyon yayınları ulusal kanallar yanında yüzlerce tematik kanalın yayınını da yapmaktadır. Günümüzde tematik kanallardaki seçenekler kadar, onlara ulaşım yollarının da çeşitlendiğini söylemek yanlış olmayacaktır. İzleyici tercih ettiği tematik kanalı ve içeriği bildiğimiz klasik televizyon vericisinden izleyebildiği gibi, yedi gün, yirmi dört saat internetten, cep telefonundan ve tablet bilgisayarlardan izleyebilmektedir. Böylece izleyicinin çeşitliliği, konuların çeşitliliği ve tematik kanallara erişimin çeşitliliği, tematik kanal yayıncılarının daha uzun süre uğraşlarını bu alanda yoğunlaştırmalarına neden olacak şeklinde değerlendirilebilir.

\section{KAYNAKÇA}

ALIGA, Christel ve WINQVIST, Karin (2003). How Women and Men Spend Their Time, Results From 13 European Countries. Statistics in Focus Theme, Eurostat. 3.12.2003

BACHSCHMIDT, Florence Le Borgne, (2003). Thematic Channels Faced with Network Digitisation. Communications and Strategies. No:49, 1st Quarter.

BAL, Evren,“Hedefe odaklanın; Segmentasyon”,http://www.soruman.com/ hedefe-odaklanin-segmentasyon/20.02.2010

CHALABY, J.K. ve SEGELL, G. (1999). "The broadcasting media in the age of risk: the advent of digital television". New Media \& Society, 1(3), ss. 351368.

CORNEO, Giacomo (2005). "Work and Television”, European Journal of Political Economy. Vol. 21, s.99 
COUNCIL of Europe (1998). Radio and Television System in the EU Member States and Switzerland. Strasbourg: Council of Europa Publishing.

ÇELIKCAN, Peyami, (2001). "Tematik Medya ve Reklam”, Akdeniz İletişim, Antalya: Akdeniz Üniversitesi İletişim Fakültesi Yayını, 2001/1.

DAVIS, William (1999). The European TV Industry in the $21^{\text {st }}$ Century. London: Informa Publishing Group.

DOSI, Arianna Imberti ve Prario, Benedetta, (2005). Digital Television Era: Is Content the King?, Televisió I Radio A L'era Digital 7, s.651

ELDENIZ, Levent (2003). Sayısal Görüntü Teknolojisinin Gelişimi ve Sayısal Video Yayıncılığı, Marmara Üniversitesi Sosyal Bilimler Enstitüsü, Yayınlanmamış Doktora Tezi.

EUROPEAN Commission (2008). Over 6.500 TV Channels Available in the Europen Union and Candidate Countries in 2008. Strasbourg: European Audivisual Observatory Press Release.

EUROPEAN Commission (2010).Growth of the Number of Television Channels and Multi-channel Platforms in Europa continues Despite the Crises. Strasbourg: European Audivisual Observatory Press Release.

FREY, Bruno S., Benesch, Christine, Stutzer Alois (2007). "Does Watching TV Make Us Happy.” Journal of Economic Psychology 28.

IP Germany (2005). Television 2005 International Keyfacts. Cologne, Germany: IP Germany.

KOTLER, Philip, Armstrong, Gary (1996). Principles of Marketing. Prentice Hall International, London.

LANGE, André (2005). The Financial Situation of Television Companies in the European Union (1994-2004), European Audivisual Observatory. Council of Europe. Strasbourg.

MAMAN, Kamil, (t.y). Tematik Kanal Patlaması. Cihan Dergi. Y11:5 Say1:18. www.cihandergi.com, 12.12.2009 
http://www.soruman.com/hedefe-odaklanin-segmentasyon/, 20.02.2010

http://www.digiturk.com.tr/kanal/tumkanallar/, 12.10.2013

PARKER, R. (1999). “The Economics of Digital TV's Future”, In GERBARG D., The economics, technology and content of digital tv, Kluwer Academic Publishers, Boston, s. 199.

PRARIO, B. (2003). "A multi-channel and multiservice television platform: the case of BSkyB". Paper presented at the 6th World Media Economics Conference, Montreal, Canada, 12-15 May.

RICHERI, G. (2004). Le prospettive della televisione digitale alla luce dell'esperienza internazionale, L'industria della comunicazione in Italia, Settimo rapporto IEM, Guerini e Associati, Torino, ss. 17-18.

“Televizyon İzlemenin Anatomisi”, http://www.medyaa.com, 26.02.2010

“Türkiye'de TV İzleme Oranları", http:// www.turkiyegazetesi.com.tr /haberdetay 02.05.2013 